\title{
Arsenic contamination in groundwater and its effects on adolescent intelligence and social competence in Bangladesh with special reference to daily drinking/cooking water intake
}

\author{
Mst. Nasrin Nahar • Tsukasa Inaoka • \\ Miho Fujimura • Chiho Watanabe • \\ Hana Shimizu $\cdot$ Sayra Tasnim • Nayar Sultana
}

Received: 25 October 2013/ Accepted: 29 October 2013/Published online: 20 November 2013

(C) The Japanese Society for Hygiene 2013

\begin{abstract}
Objective The present study aims to investigate the relationship between arsenic (As) exposure and intelligence quotient (IQ) or social competence (SC) of Bangladeshi adolescents (aged 14 or 15 years) in Sonargaon thana.

Methods Information about socioeconomic status (SES) was collected as confounding factors. To evaluate the relative contribution of As sources to total As intake, the As concentrations in urine and drinking/cooking water, and the amount of water added in cooking, were assessed on site using a food frequency questionnaire (FFQ).

Results The results confirmed that As exposure was essential to lower adolescent IQ or SC because they were negatively associated with As exposure after controlling for SES (particularly household income). Except for cooking water, the amount of drinking water varied with season and appeared to be the major As source because the As concentration in water was generally correlated with the As concentration in urine, and they were related to lower IQ or SC (even after controlling for SES). The FFQ survey revealed that rice was consumed the most frequently (more than once daily), followed by daal (bean) soup and
\end{abstract}

Mst. N. Nahar $(\bowtie)$

The United Graduate School of Agricultural Sciences,

Kagoshima University Allied to Faculty of Agriculture,

Saga University, 1 Honjo-machi, Saga, Saga 840-8502, Japan

e-mail: shapla.ru@gmail.com

T. Inaoka $\cdot$ M. Fujimura

Department of Human Ecology, Faculty of Agriculture,

Saga University, Saga, Japan

C. Watanabe $\cdot$ H. Shimizu $\cdot$ S. Tasnim $\cdot$ N. Sultana Department of Human Ecology, The University of Tokyo, Tokyo, Japan nonleafy vegetables, but fish, meat, and eggs were consumed approximately once a week. Water intake per meal from cooked rice was estimated to be $616 \mathrm{~mL} /$ person, followed by bean soup ( $258 \mathrm{~mL} /$ person) and cooked vegetables $(82 \mathrm{~mL} /$ person).

Conclusions Our results suggest that water used for cooking might be an important source of As, and the cooking process can affect the amount of As in cooked food.

Keywords Arsenic contamination - Groundwater . Adolescents · Intelligence - Social competence . Daily water intake

\section{Introduction}

The greatest threat to public health from arsenic (As) originates from contaminated groundwater. Human exposure to inorganic As is common because of its natural existence in underground water, especially in Bangladesh. The human body can be directly exposed to As through (a) ingestion of contaminated drinking water and food and (b) inhalation of metal-containing dust [1]. Arsenic can indirectly enter the body during food preparation, such as the cooking of rice and vegetables, and through irrigation water or water bodies. Previous studies identified that the cooking processes in rural areas increase the concentration of As in cooked food. The amount of As in food appears to be related to both the cooking process and the amount of As in the water used for cooking; for example, a study by Roychowdhury et al. [2] indicated that the concentration of As in cooked rice was higher than that in raw rice, suggesting a chelating effect by rice grains. Some previous studies on the estimation of As concentration in foodstuffs 
[3-5] suggest that, after drinking water, the As concentration is highest in rice, followed by vegetables. A substantial amount of water is used in cooking food using traditional cooking processes, and that water may be another important source of As. Accordingly, it cannot be overlooked. However, thus far, no study has reported on the measurement of water used in cooking under different cooking processes. Arsenic-exposed people in Bangladesh suffer from psychological suppression and social discrimination [6] in addition to the economic burden. Adverse impacts of heavy As exposure on a range of cognitive functions, including learning, memory, and concentration, as well as peripheral and central neuropathies in adults, were reported by Wasserman et al. [7]. Moreover, our previous study reported a significant relationship between urinary As concentration and intelligence quotient (IQ) as well as social competence (SC) [8]. Because the As concentration in urine reflects only the short-term exposure, it cannot indicate how long As has been acting on the body. Therefore, in addition to drinking water, other sources of As, such as cooking water, need to be investigated to analyze the relationship between the amount of As ingested and the As concentration in urine.

In the present cross-sectional study, the relationship between As concentrations in tube-well water and urine was examined. The impact of As on the IQ and SC of adolescents is reported. Food and drinking habits were surveyed using a food frequency questionnaire (FFQ) to estimate the sources of consumption of As-contaminated water. The amounts of water used for cooking and the socioeconomic status (SES) of the respondents were investigated to assess the magnitude of their influence on As exposure.

\section{Materials and methods}

Study design and data collection

The present study was conducted as a cross-sectional survey in Sonargaon thana, one of the highly As-contaminated areas in Bangladesh. The study protocol was approved by the ethics committees of the Faculty of Agriculture, Saga University and Graduate School of Medicine, University of Tokyo, Japan, and the Bangladesh Medical Research Council (BMRC). Moreover, written consent was obtained from the parents and teachers of the school before conducting this study. Most of the inhabitants depend on subsistence farming for their daily food needs as opposed to market purchases. They mainly drink and use groundwater from tube-wells in their daily life. The groundwater is severely polluted with As. The subjects were 312 adolescents between 14 and 15 years old who were randomly selected from different villages in Sonargaon thana. The study groups were composed of individuals who had been exposed to As. Data were collected in two ways. Some data were collected from the village, and other data were collected from the school. Information about socioeconomic status (SES), food habits, and drinking habits was collected via visits to each respondent's home. A structured questionnaire was used to obtain the information on socioeconomic condition and cooking process. Family demographics (e.g., family members, education, occupation, income, housing type, sanitation) were obtained from interview of the parents during enrollment of their children in the study. The structured FFQ was used to determine the respondents' food habits and consumption patterns. The source and amount of water used for preparing a given amount of food were estimated. The intelligence quotient (IQ) of the children was determined using Raven's Standard Progressive Matrices (SPM), whereas the Texas Social Behavior Inventory (TSBI) Form-A was used for measuring their score of social competence (SC). IQ and SC tests were conducted in the respondent's school. During the IQ tests, all children were administered the same series of SPM problems irrespective of age differences. They were asked to work at their own pace, uninterrupted from the beginning until the end of the test. In measuring social competence, the original translated TSBI Form-A scale was used to obtain better results. Details concerning the SPM and TSBI can be found in our previous study [8].

Water and urine analyses

All children were persuaded to provide current drinking water and spot urine samples for measurement of As concentration in water $[\mathrm{As}]_{\mathrm{w}}$ and urine $[\mathrm{As}]_{\mathrm{u}}$. Samples collected from each respondent were kept in a freezer and transported to Japan, where they were kept at $-80{ }^{\circ} \mathrm{C}$ until element determination. Water samples from each respondent's tube well were collected in $3.5-\mathrm{mL}$ polyethylene cryovials and were acidified immediately with hydrochloric acid (grade for analysis of poisonous metals, $35 \%$; Wako, Osaka, Japan) at $1 \%(\mathrm{v} / \mathrm{v})$ final concentration to inhibit deposition of ferric oxide. Urine samples were collected in 2-mL polyethylene cryovials. The collected samples were frozen and transported to Japan, where they were kept at $-30{ }^{\circ} \mathrm{C}$ until analysis. To determine the As concentration in water $[\mathrm{As}]_{\mathrm{w}}$ or in urine $[\mathrm{As}]_{\mathrm{u}}$, all the procedures were performed at the Graduate School of Medicine, University of Tokyo. Urine was diluted 20 times with a mixture of $1 \%$ nitric acid (grade for analysis of poisonous metals, $60 \%$; Wako, Osaka, Japan)/2\% 1-butanol (grade for HPLC, $99.5 \%$; Nacalai Tesque, Kyoto, Japan). Each water sample or urinary diluent was filtered using a Millex-LH $0.45-\mu \mathrm{m}$ filter (Millipore, 
Billerica, MA, USA) connected to a disposable plastic syringe. Arsenic concentration was determined by inductively coupled plasma mass spectrometry (Agilent 7500ce ICP-MS; Agilent Technologies, Santa Clara, CA, USA) with an octupole collision/reaction cell. The signal at $\mathrm{m} / \mathrm{z}$ of 75 for As was quantified in helium gas mode. ICP Multi Element Standard Solution (XVI CertiPUR; Merck, Darmstadt, Germany) was used to generate a calibration curve and prepared at three levels ranging from 2 to $50 \mu \mathrm{g} / \mathrm{L}$ in $1 \% \mathrm{HCl}$ for water or in $1 \% \mathrm{HNO}_{3}$ and $2 \% 1$-butanol for urine. Internal standard solution was prepared in each vehicle with Gallium Standard Solution (grade for AAS; Wako, Osaka, Japan) and monitored at $\mathrm{m} / \mathrm{z}$ of 71 at concentration of $25 \mu \mathrm{g} / \mathrm{L}$ by online addition via a T-piece. The detection limit (DL) ranged from 1.590 to $2.438 \mu \mathrm{g} / \mathrm{L}$ for As in water and from 0.019 to $1.216 \mu \mathrm{g} / \mathrm{L}$ for $\mathrm{As}$ in 20-fold-diluted urine, as calculated as 3 standard deviations (SDs) of the blank vehicles $(n=10)$. Analytical values under the DL were converted to half the DL. For quality assurance, NIST Standard Reference Material 1640 Natural Water, NIST Standard Reference Material 1643e Trace Elements in Water, NIST Standard Reference Material 2670a Toxic Elements in Urine (National Institute of Standards and Technology, Gaithersburg, MD, USA), NIES Certified Reference Material No. 18 Human Urine (National Institute of Environmental Studies, Tsukuba, Japan), and Seronorm Trace Elements Urine (Sero, Billingstad, Norway) were used to validate instrument performance on each running day. The observed concentrations for the reference materials were within the certified range. Urinary creatinine was determined by the Jaffe method using a LabAssay creatinine kit (Wako, Osaka, Japan). The specific gravity of urine was measured using a pocket refractometer (PAL-09S; ATAGO, Tokyo, Japan).

The values obtained for $[\mathrm{As}]_{\mathrm{w}}$ fell within the range between 0.8 (half the LOD) and $622 \mu \mathrm{g} / \mathrm{L}$. Based on some referential levels of $[\mathrm{As}]_{\mathrm{w}}$, the subjects were divided into four groups: level 1, level 2, level 3, and level 4. The value of $[\mathrm{As}]_{\mathrm{w}}$ for these groups ranged from $0.8<[\mathrm{As}]_{\mathrm{w}} \leq 10 \mu \mathrm{g} / \mathrm{L}, \quad 10<[\mathrm{As}]_{\mathrm{w}} \leq 50 \mu \mathrm{g} / \mathrm{L}, \quad 50<$ $[\mathrm{As}]_{\mathrm{w}} \leq 100 \mu \mathrm{g} / \mathrm{L}$, and $[\mathrm{As}]_{\mathrm{w}}>100 \mu \mathrm{g} / \mathrm{L}$, respectively. The facts that 10 and $50 \mu \mathrm{g} / \mathrm{L}$ are the World Health Organization (WHO) and Bangladesh national safe levels, respectively, and that symptoms are reported in the $[\mathrm{As}]_{\mathrm{w}}$ range of $60-100 \mu \mathrm{g} / \mathrm{L}$ [9] were taken into account during grouping. In contrast, [As] $]_{\mathrm{u}}$ ranged between 6 and $1,312 \mu \mathrm{g} / \mathrm{L}$. The subjects were divided into three groups by applying referential levels of $[\mathrm{As}]_{\mathrm{u}}$. The $[\mathrm{As}]_{\mathrm{u}}$ values of the low, medium, and high groups were $1<[\mathrm{As}]_{\mathrm{u}} \leq 137 \mu \mathrm{g} / \mathrm{L}$, $137<[\mathrm{As}]_{\mathrm{u}} \leq 400 \mu \mathrm{g} / \mathrm{L}$, and $400<[\mathrm{As}]_{\mathrm{u}} \leq 1,312 \mu \mathrm{g} / \mathrm{L}$, respectively. According to the referential levels, an $[\mathrm{As}]_{\mathrm{u}}$ value of $137 \mu \mathrm{g} / \mathrm{L}$ is the "noneffective level" [10] and $400 \mu \mathrm{g} / \mathrm{L}$ is the "dermatological level." There are other referential values, especially for the noneffective level; however, their use did not alter the findings observed in this study.

Measurement of cooking water

The amount of water used for food preparation was measured by visiting each household. Most households in the present survey area cook food twice in a day: once in the early morning and again in the evening. Very few of the households cook food at lunchtime. These measurements were either performed directly if the respondents were found cooking or on the next day after requests for them to cook while we were around. Raw foodstuffs and water used for cooking one meal were measured using a food weighing machine and beaker, respectively.

Statistical analysis

Data were entered into SPSS for Windows, version 18. One-way analysis of variance (ANOVA) was employed for analyzing the differences between the groups of the transformed data, whereas analysis of covariance (ANCOVA) was used to measure the effect of As concentrations in water $[\mathrm{As}]_{\mathrm{w}}$ and urine $[\mathrm{As}]_{\mathrm{u}}$ on measured IQ and SC by controlling for the socioeconomic indicators. Moreover, linear regression was used to predict the relationship between $[\mathrm{As}]_{\mathrm{w}}$ and $[\mathrm{As}]_{\mathrm{u}}$.

\section{Results}

The sociodemographics and the range of As concentrations in water $[\mathrm{As}]_{\mathrm{w}}$ and urine $[\mathrm{As}]_{\mathrm{u}}$ of the respondents are summarized in Table 1 . Approximately $56 \%$ of the subjects were female; more than $55 \%$ of the houses had corrugated tin walls and roofs. The households were mainly engaged in farming and wage labor. Though a considerable number of the households belonged to people falling into the businessman category, the parents were actually engaged in a very small-scale business such as vegetable selling and shop keeping. Bangladesh is a developing country with the majority of households falling into the low-income stratum. This study's participating households belonged to low to low-medium strata. More than $50 \%$ of the respondents were either illiterate or had only received primary education.

The mean As concentration in tube-well water was $71.7 \mu \mathrm{g} / \mathrm{L}$, which is above both the WHO and Bangladesh recommended maximum tolerable contamination levels, whereas the mean urinary As concentration was $205.3 \mu \mathrm{g} / \mathrm{L}$, which is above the noneffective level $(137 \mu \mathrm{g} / \mathrm{L})$. In general, the results in Table 1 indicate that most of the 
Table 1 Sample characteristics

\begin{tabular}{ll}
\hline Variable & No. $(\%)$ \\
\hline Subjects $(n=312)$ & $138(44.2)$ \\
Male & $174(55.8)$ \\
Female & \\
House type & $29(9.3)$ \\
Soil wall and tin roof & $173(55.4)$ \\
Corrugated tin wall and roof & $110(35.3)$ \\
Brick wall and tin roof & \\
Occupation of household head ${ }^{\mathrm{a}}$ & $66(21.2)$ \\
Wage labor & $97(31.1)$ \\
Farmer & $72(23.1)$ \\
Businessman & $58(18.6)$ \\
Paid jobs & $19(6.1)$ \\
Other & \\
Income of household head & $122(39.1)$ \\
Low & $134(42.9)$ \\
Low-medium & $56(17.9)$ \\
Medium & \\
Education of household head & $59(18.9)$ \\
Illiterate & $108(34.6)$ \\
Primary & $116(37.2)$ \\
Secondary & $29(9.3)$ \\
Arsenic concentrations, mean $(\mathrm{range})$ & \\
In water, $[\text { As }]_{\mathrm{w}}(\mu \mathrm{g} / \mathrm{L})$ & $205.3(6-2,794)$ \\
\hline
\end{tabular}

${ }^{a}$ Both father and mother are wage laborers $(n=3)$

respondents came from families with poor socioeconomic status, and thus, they are consuming highly As-contaminated tube-well water.

ANOVA was performed to investigate the influence of socioeconomic status on As contamination. The results indicated that $[\mathrm{As}]_{\mathrm{u}}$ and $[\mathrm{As}]_{\mathrm{w}}$ significantly differed by parental income $[F(2,309)=5.03, \quad p<0.01 \quad$ and $F(2,309)=5.01, p<0.01$, respectively]. This suggests that sociodemographic conditions have an influence on As exposure, and individuals with higher income can take preventive measures, such as using a water filter, changing water source, etc. However, there was no significant relationship between As contamination ([As $]_{\mathrm{u}}$ and $[\mathrm{As}]_{\mathrm{w}}$ ) and other socioeconomic indicators such as education, sanitation, and house type.

The predicted means and standard deviations of the IQ percentile and SC score for the three urinary As groups are presented in Table 2. The IQ in the high-[As $]_{\mathrm{u}}$ group did not differ from that in the medium-[As] $]_{\mathrm{u}}$ group. The percent distributions of the IQ grades for the three [As] groups (low, medium, and high; Fig. 1) indicated that a
Table 2 IQ and SC in different urinary As groups

\begin{tabular}{lcl}
\hline Variable & $\begin{array}{l}\text { IQ percentile } \\
(\text { mean } \pm \text { SD })\end{array}$ & $\begin{array}{l}\text { SC score } \\
(\text { mean } \pm \text { SD })\end{array}$ \\
\hline Urine As $(\mu \mathrm{g} / \mathrm{L})$ & & \\
& & \\
Groups & & $39.0 \pm 6.6^{\mathrm{b}}$ \\
Low $(n=171)$ & $50.5 \pm 24.3^{\mathrm{b}}$ & $35.2 \pm 7.0^{\mathrm{a}}$ \\
Medium $(n=99)$ & $40.6 \pm 18.7^{\mathrm{a}}$ & $34.7 \pm 6.2^{\mathrm{a}}$ \\
High $(n=42)$ & $40.9 \pm 19.3^{\mathrm{a}}$ & $34.7 \mathrm{call}$
\end{tabular}

Values with different letters within the same column are statistically different

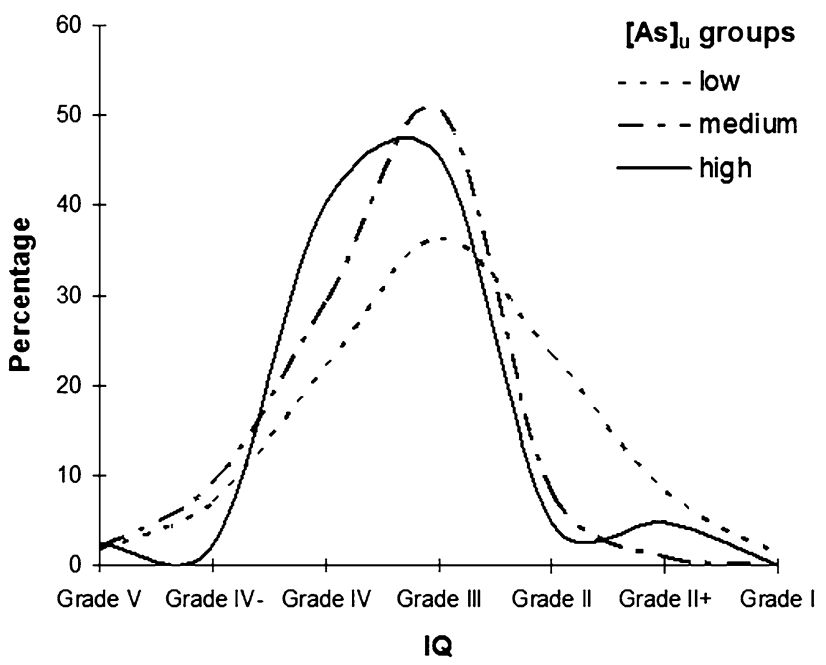

Fig. 1 Percent distribution of IQ grades among $[\mathrm{As}]_{\mathrm{u}}$ groups

very small percentage of the respondents from the high[As] $]_{\mathrm{u}}$ group possessed above-average intellectual capacity (>grade III), with most having average or below-average IQ grades. In contrast, a comparatively higher percentage of the respondents from the low-[As $]_{\mathrm{u}}$ group possessed above-average intellectual capacity. One-way ANOVA was applied to assess the differences in mean and variance, and the results indicated that the IQ percentile significantly differed among the $[\text { As }]_{\mathrm{u}}$ groups $[F(2,309)=7.7$, $p<0.01]$. A post hoc analysis for multiple comparison revealed that high $(p<0.05)$ and medium $(p<0.01)$ levels of $[\mathrm{As}]_{\mathrm{u}}$ significantly lowered the mean IQ percentile compared with the low $[\mathrm{As}]_{\mathrm{u}}$ level.

The mean SC scores (Table 2) differed among the [As $]_{\mathrm{u}}$ groups (low, medium, and high). The percent distribution of $\mathrm{SC}$ for the $[\mathrm{As}]_{\mathrm{u}}$ groups in Fig. 2 illustrates that a higher percentage of children who were averagely socially competent scored between 31 and 45 . A very small percentage (approximately 4-5\%) of the children from the high-[As] $]_{\mathrm{u}}$ group possessed high social competence (scored above 45). Comparatively, a high percentage of the children from the high-[As] $]_{\mathrm{u}}$ group scored below 30, which indicates poor 


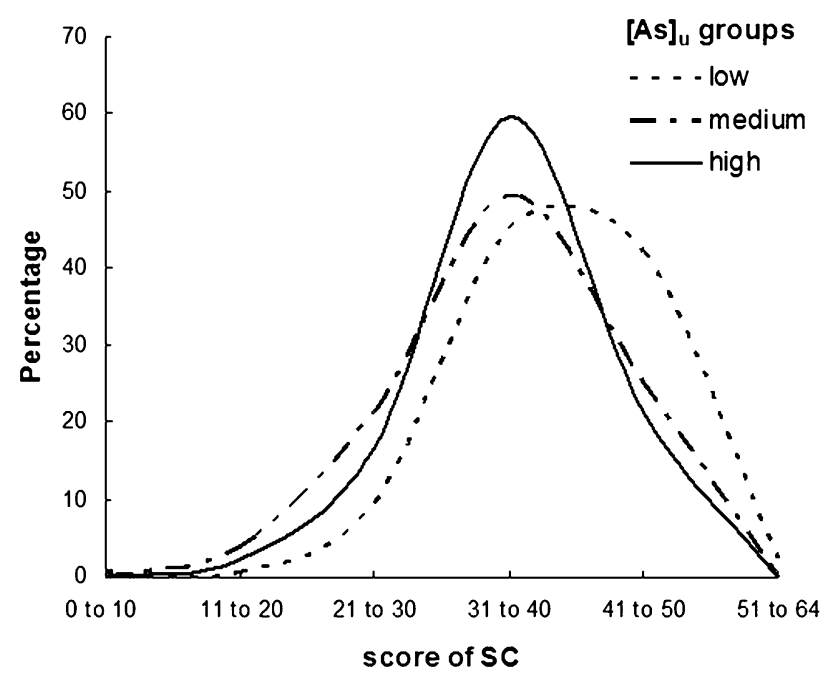

Fig. 2 Percent distribution of SC among [As] groups

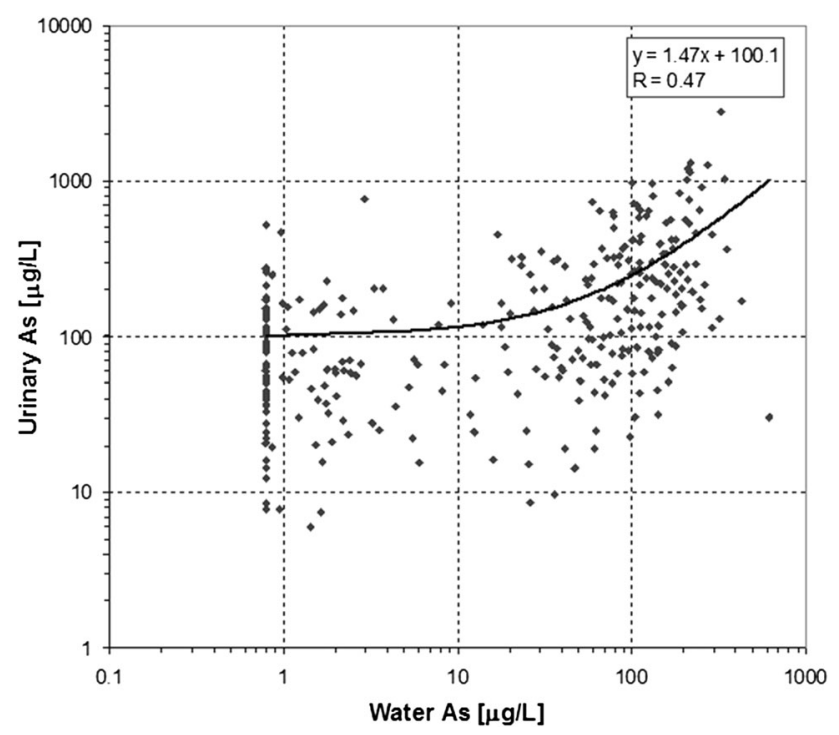

Fig. 3 Relationship between water and urinary As concentrations

social competence. One-way ANOVA revealed that SC significantly differed in the $[\mathrm{As}]_{\mathrm{u}}$ groups $[F(2,309)=14.1$, $p<0.001]$. A multiple-comparison post hoc analysis clarified that a significant reduction in SC score was found in the medium- $(p<0.001)$ and high- $[\mathrm{As}]_{\mathrm{u}}(p<0.01)$ groups in comparison with the low-[As] $]_{\mathrm{u}}$ group. Moreover, a significant effect of $[\mathrm{As}]_{\mathrm{u}}$ on the SC score $[F(2,306)=12.4, p<0.001]$ was identified after controlling for the socioeconomic indicators.

The relationship between the individual urinary ([As $\left.]_{\mathrm{u}}\right)$ and drinking water $\left([\mathrm{As}]_{\mathrm{w}}\right)$ As concentrations was analyzed, and the results are presented in Fig. 3. A positive correlation (Pearson $r=0.47, p<0.01$ ) was identified between $[\mathrm{As}]_{\mathrm{w}}$ and $[\mathrm{As}]_{\mathrm{u}}$; both variables were converted into their respective logarithmic values. It is apparent that,
Table 3 IQ and SC in different water As groups

\begin{tabular}{lll}
\hline Variable & $\begin{array}{l}\text { IQ percentile } \\
(\text { mean } \pm \text { SD })\end{array}$ & $\begin{array}{l}\text { SC score } \\
(\text { mean } \pm \text { SD })\end{array}$ \\
\hline Water As $(\mu \mathrm{g} / \mathrm{L})$ & & \\
Groups & & \\
L1 $(n=120)$ & $52.2 \pm 21.4^{\mathrm{b}}$ & $38.6 \pm 5.6^{\mathrm{b}}$ \\
L2 $(n=44)$ & $43.4 \pm 22.6^{\mathrm{a}}$ & $37.6 \pm 7.6^{\mathrm{a}}$, b \\
L3 $(n=52)$ & $44.0 \pm 22.6^{\mathrm{a}}$ & $36.1 \pm 9.0^{\mathrm{a}}$ \\
L4 $(n=96)$ & $40.7 \pm 22.3^{\mathrm{a}}$ & $35.9 \pm 6.5^{\mathrm{a}}$ \\
\hline
\end{tabular}

Values with different letters within the same column are statistically different

in the lower $[\mathrm{As}]_{\mathrm{w}}$ range (up to $10 \mu \mathrm{g} / \mathrm{L}$ ), the contribution of tube-well water to As intake is small in comparison with other unknown sources. Moreover, the results indicate a relatively constant $[\mathrm{As}]_{\mathrm{u}}$ value up to $[\mathrm{As}]_{\mathrm{w}}$ of $10 \mu \mathrm{g} / \mathrm{L}$. When $[\mathrm{As}]_{\mathrm{w}}$ exceeds $10 \mu \mathrm{g} / \mathrm{L}$, the deviation also increases rather than remaining constant. This suggests the existence of other sources of As intake.

We further investigated the effect of As concentration in water $[\mathrm{As}]_{\mathrm{w}}$ on IQ and SC. The mean IQ percentile $(50.5 \pm 24.3)$ presented in Table 3 for the level 1 (L1) $[\mathrm{As}]_{\mathrm{w}}$ group was higher than that of other groups. However, the mean IQ scores among the L2, L3, and L4 $[\mathrm{As}]_{\mathrm{w}}$ groups were nearly the same. It was found that water As concentration $\left([\mathrm{As}]_{\mathrm{w}}\right.$ ) had a significant influence on IQ $[F(3,308)=5.4, p<0.01]$. A planned contrast indicated that the mean IQ score of the L1 group significantly differed from the L2 and L4 groups at $p<0.05$ and $p<0.01$, respectively. Moreover, the mean IQ percentile in the L4 group was significantly lower than in the L1 group $(p<0.01)$. Finally, controlling for socioeconomic indicators such as parental education, occupation, and income, the ANCOVA revealed that there was a significant effect of $[\mathrm{As}]_{\mathrm{w}}$ on IQ $[F(2,306)=6, p<0.01]$. This indicates that consumption of a high concentration of As through groundwater significantly lowered the mean IQ of the children. On the contrary, a similar trend in mean SC scores was found among the $[\mathrm{As}]_{\mathrm{w}}$ groups. SC significantly differed in the $[\mathrm{As}]_{\mathrm{w}}[F(3,308)=3.4, p<0.05]$ groups, and the mean SC score in group L4 significantly differed from the L1 group $(p<0.05)$. However, no significant effect of $[\mathrm{As}]_{\mathrm{w}}$ on SC was found after controlling for the socioeconomic indicators.

To identify other sources of As, food consumption patterns were assessed by FFQ and the 24-h recall method. According to the 24-h recall method (Fig. 4a), $62 \%$ of the respondents consumed rice and $32 \%$ consumed daal three times per day. The FFQ results (Fig. 4b) indicated that $100 \%$ of respondents consumed rice 5-7 days per week, 
followed by nonleafy vegetables $(90 \%)$ and then daal $(61 \%)$

The amount of water used in cooking was measured using a food preparation survey on site (Table 4). Rice, the major Bangladeshi food, is usually cooked with either "fixed water" or "excess water." In the former process, water is added at approximately 2.5 times the volume by weight of rice. This rate is much higher than the 1.3 used in Japan [11]. In the excess water process, water is added at approximately three to four times the volume by weight of rice, and when the rice has been boiled, the excess water is discarded. In our study area, most of the households
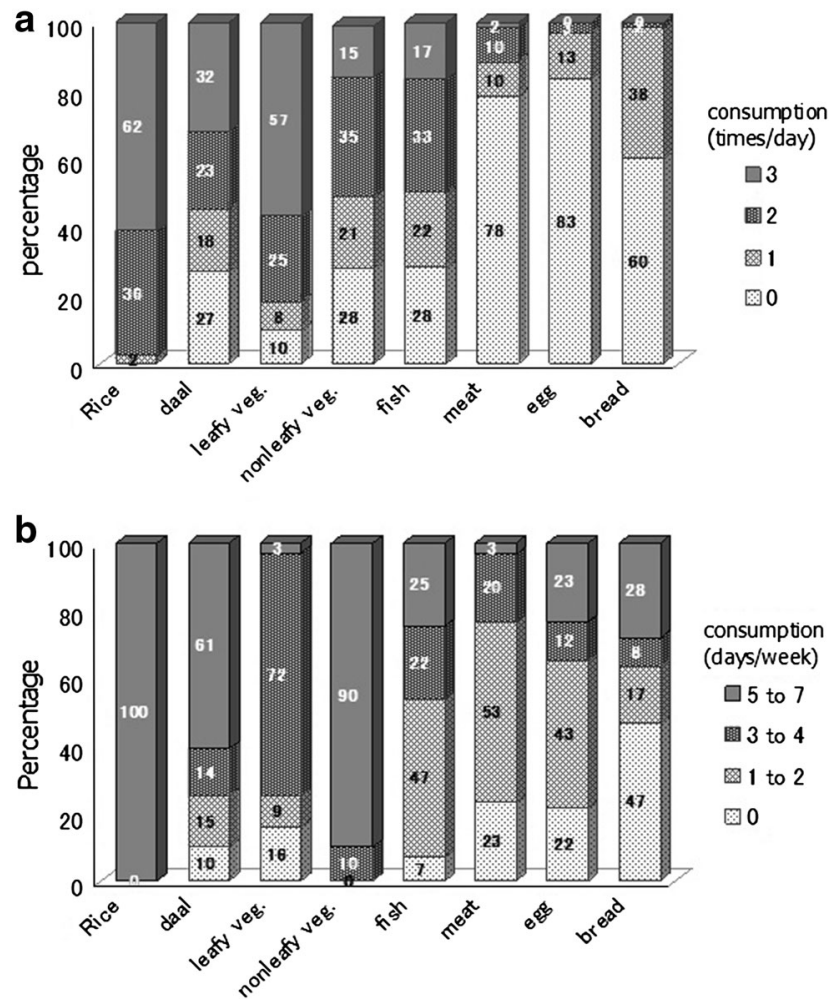

Fig. 4 Food consumption pattern according to 24-h recall (a) and FFQ (b) cooked rice with "excess water." As shown in Table 4, an average of $1,165 \mathrm{~g}$ rice was boiled with $3,827 \mathrm{~mL}$ water initially. After discarding the excess water, $3,312 \mathrm{~mL}$ water (approximately 2.8 times the volume by weight of rice) was absorbed in the cooked rice. Curry is the most common cooking recipe, including either meat, fish, egg or vegetables. A large amount of water is also required when cooking curry. Another common recipe is daal soup with different types of pulses/lentils. Water is not discarded after cooking either curry or daal soup. For daal soup, the ratio of lentils to used water is approximately $1 / 6$, whereas the ratio for vegetables is $1 / 0.8$. Based on the data obtained from 24-h recall and the FFQ, the weekly consumption of water from cooked foods was estimated (Table 4). As shown in the rightmost column, the major source of water consumption was cooked rice, followed by daal soup. The contribution of water from different types of curry and chapati was minor because they were not often consumed.

\section{Discussion}

This study confirmed the impact of urinary As concentration on the IQ or SC of Bangladeshi adolescents. High concentration of As significantly lowered the mean IQ percentile because As is neurotoxic and can damage brain functions, as reported in some biomedical studies $[12,13]$. Another possibility is that maternal exposure to As resulted in damaged brain function in their children. Previously, it was mentioned that very few works have reported on the impact of As exposure on children in Bangladesh; the most cited study was conducted by Wasserman et al. [7]. They conducted their study on As exposure in 10-year-old children and found a stronger association of IQ with As in tube-well water than with urinary As. However, in our study, a stronger association was found for IQ with urinary As than with As in tube-well water. The existence of a

Table 4 Water added in cooking foods and estimated water consumption by recipe

\begin{tabular}{|c|c|c|c|c|c|}
\hline Food & $\begin{array}{l}\text { Amount }(\mathrm{g}) \\
(\text { Mean } \pm \mathrm{SD})\end{array}$ & $\begin{array}{l}\text { Water added }(\mathrm{mL}) \\
(\text { Mean } \pm \mathrm{SD})\end{array}$ & $\begin{array}{l}\text { Actual added water }(\mathrm{mL}) \\
\text { [relative difference] } \\
(\text { Mean } \pm \mathrm{SD})\end{array}$ & $\begin{array}{l}\text { Water consumption } \\
(\mathrm{mL} / \text { person/meal }) \\
(\text { Mean } \pm \mathrm{SD})\end{array}$ & $\begin{array}{l}\text { Water consumption } \\
(\mathrm{mL} / \text { person/week) } \\
\text { Mean } \pm \mathrm{SD})\end{array}$ \\
\hline Rice $(n=177)$ & $1,165 \pm 364$ & $3,827 \pm 1,097$ & $3,312 \pm 1,057[2.8]$ & $616 \pm 133$ & $12,926 \pm 2,797$ \\
\hline Daal soup $(n=177)$ & $234 \pm 112$ & $1,405 \pm 559$ & $1,405 \pm 559[6.0]$ & $258 \pm 62$ & $2,061 \pm 496$ \\
\hline Vegetable curry $(n=172)$ & $555 \pm 290$ & $437 \pm 220$ & $437 \pm 220[0.8]$ & $82 \pm 38$ & $572 \pm 266$ \\
\hline Fish curry $(n=90)$ & $466 \pm 178$ & $508 \pm 242$ & $508 \pm 242[1.1]$ & $98 \pm 50$ & $293 \pm 150$ \\
\hline Meat curry $(n=52)$ & $853 \pm 326$ & $880 \pm 404$ & $880 \pm 404[1.0]$ & $161 \pm 62$ & $129 \pm 50$ \\
\hline Egg curry $(n=28)^{\mathrm{a}}$ & $5 \pm 1.3$ & $219 \pm 52$ & $219 \pm 52[1.8]$ & $80 \pm 37$ & $32 \pm 15$ \\
\hline Chapati $(n=26)$ & $730 \pm 399$ & $227 \pm 112$ & $227 \pm 112[0.3]$ & $43 \pm 19$ & $34 \pm 15$ \\
\hline
\end{tabular}

Based on data obtained from 24-h recall and FFQ

${ }^{\text {a }}$ Assuming 1 egg $=40 \mathrm{~g}$ 
stronger association between IQ and urinary As is more reasonable because the urinary As concentration reflects the total ingestion of As from all possible sources. In contrast, apart from our previous study [8], there has been little work on the effect of As exposure on SC. We identified a significant association of urinary As concentration with SC. A more detailed discussion on the lowering of IQ or SC scores due to the influence of As contamination can be found in our previous study [8].

In the present survey, socioeconomic status (SES) had an influence on exposure to As contamination via groundwater because rural people in the present survey area could not take any steps to use As-free water because of their poor socioeconomic conditions (SEC). In 2011, Shakeel et al. [14] reported that poor families are exposed to As through drinking water and have less access to alternative safe drinking water sources. Their poor SEC may, therefore, propagate As poisoning, though some researchers state that As poisoning also results in deteriorating SEC because of the requisite spending of a larger proportion of money on treatment, job loss, barriers accessing new jobs, and social isolation, among other factors.

Our study indicated that drinking water and urinary As concentrations $\left([\mathrm{As}]_{\mathrm{w}}\right.$ and $[\mathrm{As}]_{\mathrm{u}}$ ) were fairly correlated. Because $[\mathrm{As}]_{\mathrm{u}}$ reflects the recent exposure from all possible sources, this correlation indicates that the respondents were exposed to As not solely through drinking water. Prior to data collection, some tube-well water from different villages was randomly inspected using an As test NIPSOM kit to assess the As contamination level. Surprisingly, the As concentration $[\mathrm{As}]_{\mathrm{w}}$ in some of the respondents' tube-well water was determined to be in the safe range; however, their urine test results revealed the presence of a high concentration of As $[\mathrm{As}]_{\mathrm{u}}$. This indicates that they are ingesting As from other sources, such as food and water used for cooking. When asked about their cooking water sources, surprisingly, we found that they had stopped drinking water from contaminated tube wells but had continued to use that contaminated tube-well water for cooking purposes. They believed that the heat in the cooking process evaporates and destroys the As from water, as occurs with some microbes.

Children aged between 14 and 15 years old consume $3.2 \mathrm{~L} /$ day water on average during summer. A previous study in children older than 10 years old reported that the daily water intake via direct drinking on an average day was $2.7 \mathrm{~L} /$ day $(1.7-3.3 \mathrm{~L} /$ day $)$ and $2 \mathrm{~L}$ /day (1.2-2.7 L/ day) for male and female children, respectively [15]. Moreover, according to some previous studies, the contribution of raw food to As exposure based on daily intake is minor compared with the amount from drinking water. For example, the mean concentrations of As in rice of different districts of Bangladesh ranged from 100 to $950 \mu \mathrm{g} / \mathrm{kg}$ [16].
In another study, the mean concentration of As was actually 10-30 \% higher because of the processing of raw rice with As-contaminated water [17]. Although it is apparent that drinking water is the major source of As for the population living in As-affected areas in Bangladesh, our results suggest that the water used in cooking could be another way that As is consumed. Many reports have relied on the concentrations of As in drinking water [18-24] as a surrogate for human exposure; however, the potential individual consumption of water and additional exposure through cooked food should not be neglected. Here, it is worth mentioning that, thus far, the present study is the first systematic work to evaluate the relative contribution of As sources to total As intake by assessing the As concentration in drinking water and the proportion of water added in cooking processes. The amount of water used for cooking under different cooking processes was measured. From our FFQ data, we found that respondents ate rice more than once a day. Their next most frequent food type was daal soup and then nonleafy vegetables, at almost once-a-day frequency. The results of the cooking water estimation suggested that a large amount of water, which is mainly As-contaminated groundwater, is used to cook food. Thus, the cooking water may have an influence on the total As intake. In our present work, cooking water samples were not collected to measure As concentration; however, it is necessary to evaluate the proper relationship between urinary $[\mathrm{As}]_{\mathrm{u}}$ and water $[\mathrm{As}]_{\mathrm{w}}$ concentrations. Future research should include estimation of As intake from all possible sources, including drinking water and water used for cooking.

Finally, since the people in the present survey area are exposed to high levels of As-contaminated tube-well water, our findings can play an important role in facilitating appropriate steps for mitigation of As poisoning from all possible sources, such as drinking and cooking water, which will thus reduce their total As intake and, accordingly, improve rural livelihood in Bangladesh. The most important action in affected communities is prevention of further exposure to As by provision of safe water supplies for drinking, food preparation, and irrigation of food crops. Moreover, we hope that our findings will add a new sense of urgency to mitigate As exposure in Bangladesh and other parts of the world where consumption of As-contaminated groundwater is prevalent.

Acknowledgments The survey work described in this manuscript was financially supported by the Ministry of Education, Culture, Sports, Science, and Technology of Japan. The authors wish to thank all the students, their parents, and the staff from all schools for their participation and assistance. We wish to especially thank the Department of Human Ecology, Graduate School of Medical Sciences, The University of Tokyo, Japan for helping analyze the water and urine samples. We would also like to thank the Government of 
Japan for awarding a Monbukagakusho scholarship to Mst. Nasrin Nahar, one of the authors.

Conflict of interest The authors have no conflicting interests.

\section{References}

1. Khan SI, Ahmed AKM, Yunus M, Rahman M, Hore SK, Vahter $\mathrm{M}$, et al. Arsenic and cadmium in food-chain in Bangladesh-an exploratory study. J Health Popul Nutr. 2010;28(6):578-84.

2. Roychowdhury T, Uchino T, Tokunaga H, Ando M. Survey of arsenic in food composites from an arsenic-affected area of West Bengal, India. Food Chem Toxicol. 2002;40:1611-21.

3. Khan MAR, Misbahuddin MS, Khandker S, Ifthaker-Al-Mahmud. Arsenic estimation in foodstuffs of arsenic exposed areas in Bangladesh. In: Misbahuddin M, editor. Applied research on arsenic in Bangladesh. Dhaka: WHO; 2007. p. 31-42.

4. Huq SMI, Joardar JC, Parvin S, Correl R, Naidu R. Arsenic contamination in food chain: transfer of arsenic into food materials through groundwater irrigation. $\mathrm{J}$ Health Popul Nutr. 2006;24:305-16.

5. Das HK, Mitra AK, Sengupta PK, Hossain A, Islam F, Rabbani GH. Arsenic concentrations in rice, vegetables, and fish in Bangladesh: a preliminary study. Environ Int. 2004;30:383-7.

6. Keya MK, Harun SMR. Psychological situation of arsenic affected people of rural Bangladesh. Bangladesh Psychol Stud. 2008;13:55-66.

7. Wasserman GA, Liu X, Parvez F, Ahsan H, Factor-Litvak P, van Geen A, et al. Water arsenic exposure and children's intellectual function in Araihazar, Bangladesh. Environ Health Perspect. 2004;112(13):1329-33.

8. Nahar MN, Inaoka T. Intelligence quotient and social competence of junior high school students drinking arsenic contaminated groundwater in Bangladesh. Res $\mathrm{J}$ Environ Toxicol. 2012;6:110-21.

9. The World Bank. Arsenic contamination of groundwater in South and East Asian countries, vol. II, Technical Report No. 31303; 2005.

10. Miyazaki K, Ushijima K, Kadono T, Inaoka T, Watanabe C, Ohtsuka R. Negative correlation between urinary selenium and arsenic levels of the residents living in an arsenic-contaminated area in Bangladesh. J Health Sci. 2003;49:239-42.
11. Watanabe C, Kawata A, Sudo N, Sekiyama M, Inaoka T, Bae M, et al. Water intake in an Asian population living in arsenic-contaminated area. Toxicol Appl Pharmacol. 2004;198:272-82.

12. Vahidnia A, Van Der Voet GB, DeWolff FA. Arsenic neurotoxicity-a review. Hum Exp Toxicol. 2007;26:823-32.

13. Rocha RA, Gimeno-Alcaniz JV, Martín-Ibanez R, Canals JM, Vélez D, Devesa V. Arsenic and fluoride induce neural progenitor cell apoptosis. Toxicol Lett. 2011;203:237-44.

14. Shakeel AIM, Amal KH. The socioeconomic impact of arsenic poisoning in Bangladesh. J Toxicol Environ Health Sci. 2011;3(2):65-73.

15. Ohno K, Yanase T, Matsuo Y, Kimura T, Rahman MH, Yasumoto M, et al. Arsenic intake via water and food by a population living in an arsenic-affected area of Bangladesh. Sci Total Environ. 2007;381:68-76.

16. Williams PN, Price AH, Raab A, Hossain SA, Feldmann J, Meharg AA. Variation in arsenic specification and concentration in paddy rice related to dietary exposure. Environ Sci Technol. 2005;39:5531-40.

17. Misbahuddin M. Consumption of arsenic through cooked rice. Lancet. 2003;361:435-6.

18. Mazumder DG, Haque NR, Ghosh N, Dc BK, Santra A, Chakraborty $\mathrm{D}$, et al. Arsenic level in drinking water and the prevalence of skin lesions in West Bengal, India. Int J Public Health. 1998;81:328-34.

19. Hopenhayn-Rich C, Biggs ML, Smith AH. Lung and kidney cancer mortality associated with arsenic in drinking water in Córdoba, Argentina. Int J Epidemiol. 1998;27:561-9.

20. Kurttio P, Komulainen H, Hakala E, Kahelin H, Pekkanen J. Urinary excretion of arsenic species after exposure to arsenic present in drinking water. Arch Environ Contam Toxicol. 1998;34:297-305.

21. Tondel M, Rahman M, Magnuson A, Chowdhury IA, Faruquee MH, Ahmad SA. The relationship of arsenic levels in drinking water and the prevalence rate of skin lesions in Bangladesh. Environ Health Perspect. 1999;107:727-9.

22. Bhattacharya P, Jacks G, Ahmed KM, Routh J, Khan AA. Arsenic in groundwater of the Bengal delta plain aquifers in Bangladesh. Bull Environ Contam Toxicol. 2002;69:538-45.

23. Anawar HM, Akai J, Mostofa KMG, Safiullah S, Tareq SM. Arsenic poisoning in groundwater: health risk and geochemical sources in Bangladesh. Environ Int. 2002;27:597-604.

24. Frisbie HS, Ortega R, Maynard MD, Sarkar B. The concentrations of arsenic and other toxic elements in Bangladesh's drinking water. Environ Health Perspect. 2002;110(11):1147-53. 